\title{
Azithromycin and Other Macrolides for Prevention of Bronchopulmonary Dysplasia: A Systematic Review and Meta-Analysis
}

\author{
Vrinda Nair ${ }^{a}$ Prakash Loganathan ${ }^{a}$ Amuchou Singh Soraisham ${ }^{a}$ b \\ a Section of Neonatology, Department of Pediatrics, University of Calgary, and b Alberta Children's Hospital Research \\ Institute for Child and Maternal Health, Calgary, Alta., Canada
}

\section{Key Words}

Azithromycin · Bronchopulmonary dysplasia - Macrolides .

Preterm infants

\begin{abstract}
Background and Objective: Ureaplasma spp. infection has been associated with bronchopulmonary dysplasia (BPD) in preterm infants. Macrolides have been used for the treatment of Ureaplasma spp. infection, with an intention to prevent $\mathrm{BPD}$. The objective of this meta-analysis is to evaluate the use of macrolides in the prevention of BPD in preterm infants. Methods: We searched MEDLINE, EMBASE, and Cochrane Central Register of Controlled Trials, abstracts of the major pediatric society meetings and bibliographies of retrieved articles. We included randomized controlled trials assessing the effects of macrolides therapy on BPD in preterm infants. A random/fixed-effect model was used to synthesize predefined outcomes. Results: Six studies involving 469 preterm infants were eligible for the analysis. Macrolides when used prophylactically (4 studies) did not show significant reduction in BPD (risk ratio, $\mathrm{RR}, 0.88,95 \%$ confidence interval, $\mathrm{Cl}, 0.75-1.03$ ), death (RR $0.89,95 \% \mathrm{Cl} 0.79-1.01$ ) or in the composite outcome of BPD/death. Similarly, there was no significant reduction in $\mathrm{BPD}$ ( $\mathrm{RR} 0.64,95 \% \mathrm{Cl} 0.31-1.31$ ) or
\end{abstract}

the composite outcome of BPD/death (RR $0.41,95 \% \mathrm{Cl} 0.05-$ 3.13), when macrolides were used in Ureaplasma-positive infants. However, prophylactic azithromycin therapy (3 studies) was associated with significant reduction in BPD (RR $0.83,95 \% \mathrm{Cl} 0.71-0.97$; number needed to treat, NNT, 10 ) and composite outcome of BPD/death (RR $0.86,95 \% \mathrm{Cl} 0.77$ 0.97; NNT 10). Conclusion: This meta-analysis demonstrates prophylactic azithromycin therapy was associated with statistically significant reduction in BPD and the composite outcome of BPD/death in preterm infants. However, given the limited information on pharmacokinetics and potential harmful effects, further studies should be done before routine use of azithromycin in the neonatal population.

(c) 2014 S. Karger AG, Basel

\section{Introduction}

Bronchopulmonary dysplasia (BPD) remains a major health problem in preterm infants resulting in increased health care costs, prolonged hospital stay, and effects on subsequent growth and neurodevelopment [1]. The incidence of BPD vary among different centers, ranging from 44 to $77 \%$ in infants weighing $<1,000 \mathrm{~g}$ [2]. Chorioamnionitis is an important risk factor associated with de-

\section{KARGER}

E-Mail karger@karger.com

www.karger.com/neo
(C) 2014 S. Karger AG, Basel

$1661-7800 / 14 / 1064-0337 \$ 39.50 / 0$
Dr. Amuchou Singh Soraisham Foothills Medical Centre Room C-211, 1403, 29th Street, NW Calgary, AB T2N 2T9 (Canada)

E-Mail asoraish@ucalgary.ca 
velopment of BPD [3]. Ureaplasma spp. are the most common organisms isolated from women with chorioamnionitis $[4,5]$ and have been associated with increased risk for preterm labor. Ureaplasma spp. colonization has been associated with the development of pulmonary inflammation and BPD in preterm infants [6]. Two metaanalyses have suggested an association between Ureaplasma infection and the development of BPD $[7,8]$. Intrauterine infection with Ureaplasma spp. can lead to altered lung development, prolonged inflammatory response and increased fibrotic reaction in animals $[9,10]$. Ureaplasma infection induces production of tumor necrosis factor- $\alpha$ and interleukin-6 [11] and also causes apoptosis of human type 2 lung epithelial cells and lung macrophages [12]. Apart from BPD, Ureaplasma has also been associated with retinopathy of prematurity [13], intraventricular hemorrhage [14, 15], necrotizing enterocolitis (NEC) [16] and adverse neurodevelopmental outcome [17]; all these associations could be attributed to the ability of Ureaplasma to elicit an inflammatory reaction.

Macrolides are antimicrobial agents with anti-inflammatory actions, which may play a role in preventing BPD $[18,19]$. The commonly used macrolides for treatment of Ureaplasma spp. in the neonatal period include erythromycin, azithromycin and clarithromycin. Macrolides have been successfully used in treatment of inflammatory lung diseases such as chronic obstructive pulmonary disease and cystic fibrosis. There is limited evidence regarding the use of macrolides for the treatment of Ureaplasma colonization or the prophylactic use (irrespective of Ureaplasma culture status) for the prevention of BPD in preterm infants. Few clinical trials have reported the effect of macrolides in the prevention of BPD with conflicting results [20-25]. A Cochrane review on erythromycin for the prevention of BPD included 2 studies and reported no significant reduction in BPD or death [26]. Since then, 4 randomized control trials have been published between 2007 and 2013 using various types of macrolides for prevention of BPD [22-25]. The objective of this systematic review and meta-analysis is to evaluate the current evidence on the use of macrolides in the prevention of BPD in preterm infants.

\section{Material and Methods}

\section{Study Eligibility}

We included randomized or quasi-randomized controlled trials evaluating either prophylactic or therapeutic use of macrolides for the prevention of BPD and/or death in preterm infants. We excluded review articles, case reports, meta-analyses, pharmacokinetic studies, studies showing only clearance of Ureaplasma, use of macrolides for obstetric purposes and for feeding intolerance in infants.

\section{Data Sources}

We did a comprehensive search in the following computerized biomedical databases: Ovid MEDLINE (1946-2013), EMBASE (1974-2013), Cochrane Central Register of Controlled Trials (December 2013), International Pharmaceutical Abstracts (19702013), abstracts from Pediatric Academic Society meeting and European Society for Pediatric Research (last 10 years). Searches were supplemented by scanning bibliographies. We used boolean operators (and, or, not) as needed. We performed text word/MeSH and explode search strategy to optimize the literature retrieval. We used the following keywords: Infant, Premature/[preterm infant terms], exp Macrolides/[macrolide terms] (erythromycin, azithromycin, clarithromycin, roxithromycin, and troleandomycin), $\mathrm{BPD} /$ bronchopulmonary dysplasia, CLD/chronic lung disease. We limited our search to human studies only. No language restrictions were applied.

\section{Study Selection and Data Extraction}

All the abstracts identified by online searches were screened by two reviewers (V.N., P.L.) to determine the eligibility for further review. Data extraction was performed independently by the two investigators (V.N., P.L.) by using a standard data collection form. Discrepancies in eligibility screening, data extraction, data entry and analysis were resolved by discussion. We used Preferred Reporting Items for Systematic Reviews and Meta-Analyses (PRISMA) for study selection process.

\section{Study Quality Assessment}

Two investigators independently assessed the quality of each study using the Cochrane collaboration's tool for assessing risk of bias in randomized trials. Methodological quality was evaluated by assessing selection bias (random sequence generation and allocation concealment), performance bias (blinding of participants and personnel), attrition bias (incomplete outcome data), detection bias (blinding of outcome), reporting bias, and other possible sources of bias. Studies were considered at low risk of bias if they were at low risk of both selection and allocation bias and one of detection, performance, or reporting bias. Studies were otherwise classified as high risk.

\section{Data Synthesis}

We used Revman 5.2 software for all our statistical analysis. We performed the analyses to evaluate the effect of macrolides on the incidence of BPD, death and the composite outcome of BPD/death when used prophylactically (irrespective of Ureaplasma status) and in Ureaplasma-positive preterm infants (therapeutic use). We also performed a separate analysis on the effect of azithromycin on these outcomes. All the treatment effects of categorical variables were reported as risk ratio (RR) with 95\% confidence interval (CI) using Mantel-Haenszel method. $\mathrm{I}^{2}$ statistic was used to assess the heterogeneity ( $\mathrm{I}^{2}$ ranges between 0 and $100 \%$, with lower values representing less heterogeneity). We used a random-effect model if there was significant heterogeneity $\left(\mathrm{I}^{2} \geq 50 \%\right)$ and a fixed-effect model when $\mathrm{I}^{2}$ was less than $50 \%$. 
Fig. 1. Flow diagram for selection of studies.

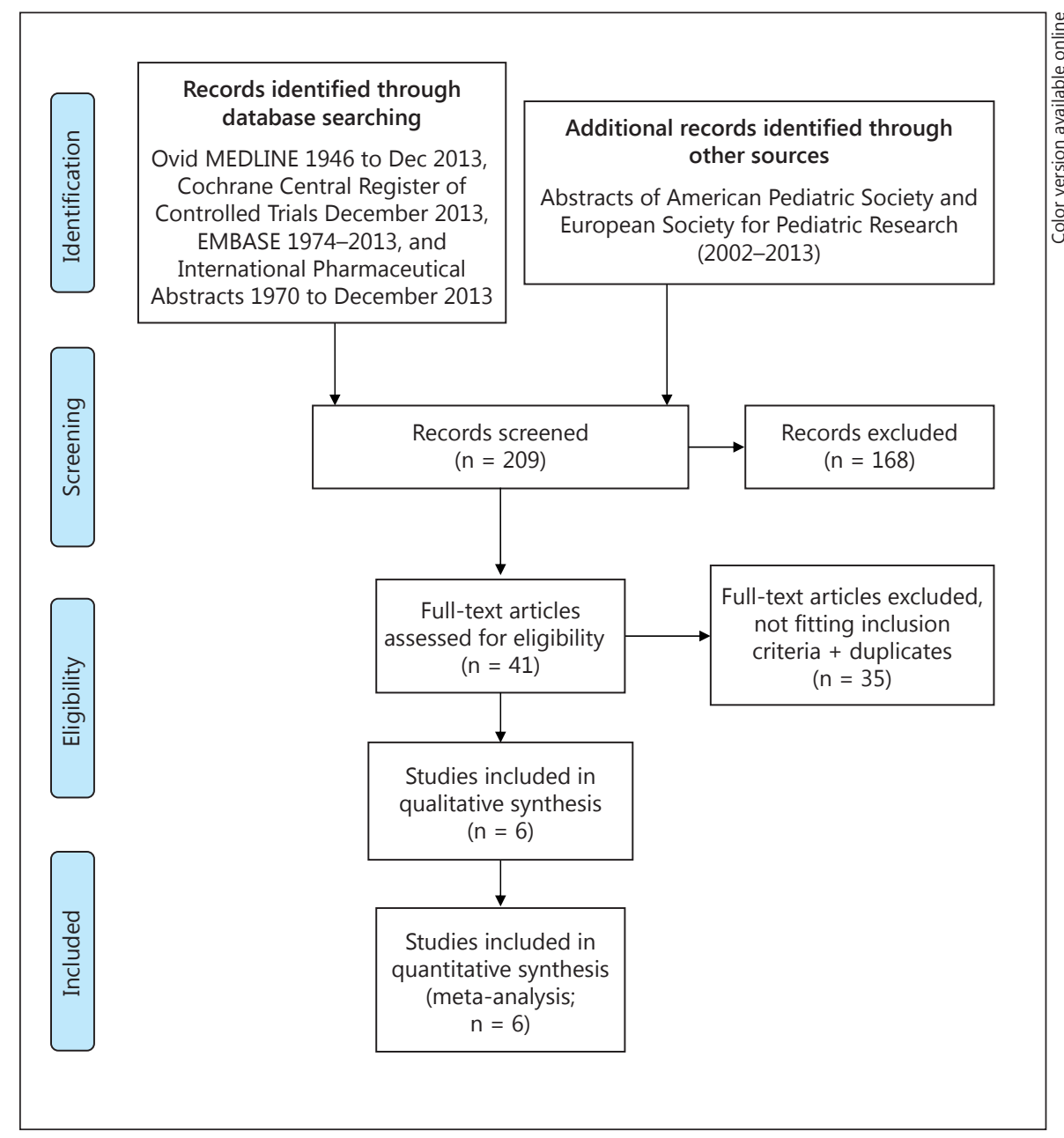

\section{Results}

A total of 209 abstracts were screened. Six studies met inclusion criteria and were included in the meta-analysis. A manual search of references cited in these articles did not yield new eligible articles. Figure 1 shows the flow diagram of studies identified in the PRISMA format. Of the 6 studies, 4 examined the effect of prophylactic use of macrolides on the incidence of BPD [20,22-24]. Ballard et al. [23] also evaluated the effect of azithromycin in a subgroup of infants who were Ureaplasma positive. A total of 3 studies reported the effect of macrolides on the incidence of BPD among Ureaplasma-positive preterm infants [21, 23, 25].

\section{Study Characteristics}

The characteristics of the included study are shown in table 1 . Three studies compared azithromycin with placebo [22-24]. Two studies compared erythromycin with placebo $[20,21]$ and only one study compared clarithromycin with placebo [25]. Two studies specifically used macrolides in infants colonized with Ureaplasma [21,25] and remaining studies used macrolides prophylactically in infants irrespective of Ureaplasma status.

Table 2 shows the comparison of the study quality. Only 2 studies were of high quality satisfying $\geq 4$ out of 8 criteria $[23,24]$, and the remaining studies were of either low or unclear quality. There was no significant publication bias as assessed by the funnel plot (fig. 2).

\section{Primary Outcomes}

Effect of Prophylactic Azithromycin on Outcomes

Three studies were included in the analysis [22-24]. The prophylactic azithromycin use demonstrated a significant reduction in BPD (RR 0.83, 95\% CI 0.71-0.97; number needed to treat, NNT, 10) and the composite outcome of BPD/death (RR 0.86, 95\% CI 0.77-0.97; NNT 10; 
Table 1. Characteristics of the trials included in the analysis

\begin{tabular}{|c|c|c|c|c|c|c|}
\hline Source & Inclusion criteria & $\begin{array}{l}\text { Ureaplasma } \\
\text { colonization rate and } \\
\text { detection technique }\end{array}$ & $\begin{array}{l}\text { Macrolides } \\
\text { used }\end{array}$ & Dosage and duration & $\begin{array}{l}\text { Macrolide } \\
\text { initiation }\end{array}$ & Primary outcome \\
\hline $\begin{array}{l}\text { Ballard et al., } \\
\text { USA [22] }\end{array}$ & $\begin{array}{l}B W<1,000 \mathrm{~g} \text { and } \\
\text { ventilated }\end{array}$ & $\begin{array}{l}19 \% \text {; tracheal aspirate } \\
\text { cultures }\end{array}$ & azithromycin & $10 \mathrm{mg} / \mathrm{kg} /$ day $\times 7$ days $^{1}$ & $0-72 \mathrm{~h}$ of age & BPD \\
\hline $\begin{array}{l}\text { Ballard et al. } \\
\text { [23], USA }\end{array}$ & $\begin{array}{l}\mathrm{BW}<1,250 \mathrm{~g} \\
\text { and ventilated }\end{array}$ & $\begin{array}{l}35 \% \text {; tracheal aspirate } \\
\text { PCR }\end{array}$ & azithromycin & $10 \mathrm{mg} / \mathrm{kg} /$ day $\times 7$ days $^{1}$ & $0-72 \mathrm{~h}$ of age & BPD \\
\hline
\end{tabular}

$\mathrm{IMV}=$ Intermittent mandatory ventilation; $\mathrm{BW}=$ body weight. ${ }^{1}$ Followed by $5 \mathrm{mg} / \mathrm{kg} /$ day until the infant no longer required $\mathrm{IMV}$ or supplemental $\mathrm{O}_{2}$, to a maximum of 6 weeks.

Table 2. Risk of bias assessment
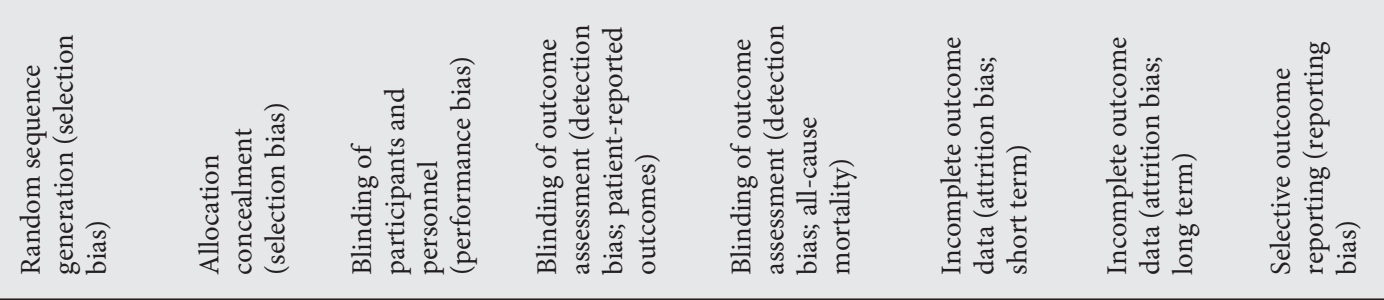

Jonsson et al. [21]

Lyon et al. [20]

Ballard et al. [22]

Ballard et al. [23]

Ozdemir et al. [25]

Gharehbaghi et al. [24]

$\begin{array}{ll}- & - \\ + & + \\ + & + \\ + & + \\ + & +\end{array}$

$\begin{array}{ll}- & \\ + & ? \\ + & ? \\ + & ? \\ + & ? \\ + & ?\end{array}$

-
$?$
$?$
$?$
$?$
+

fig. 3,4$)$. There was no significant reduction in mortality (RR 1.00, 95\% CI 0.66-1.50; fig. 5).

\section{Effect of Prophylactic Macrolides on Outcomes}

Four studies ( 3 studies with azithromycin and 1 study with erythromycin) were included involving 373 infants, 191 infants in the macrolides group and 182 infants in the control group [20, 22-24]. A higher proportion of neonates in the control group developed BPD as compared with macrolides group ( 55 vs. $49 \%$ ). However, there was no statistically significant reduction in BPD (RR 0.88, 95\% CI 0.75-1.03), death (RR 1.00, 95\% CI 0.68-1.48) or the composite outcome of BPD/death (RR $0.89,95 \%$ CI 0.79-1.01; fig. 6-8). 
Fig. 2. Funnel plot for publication bias.

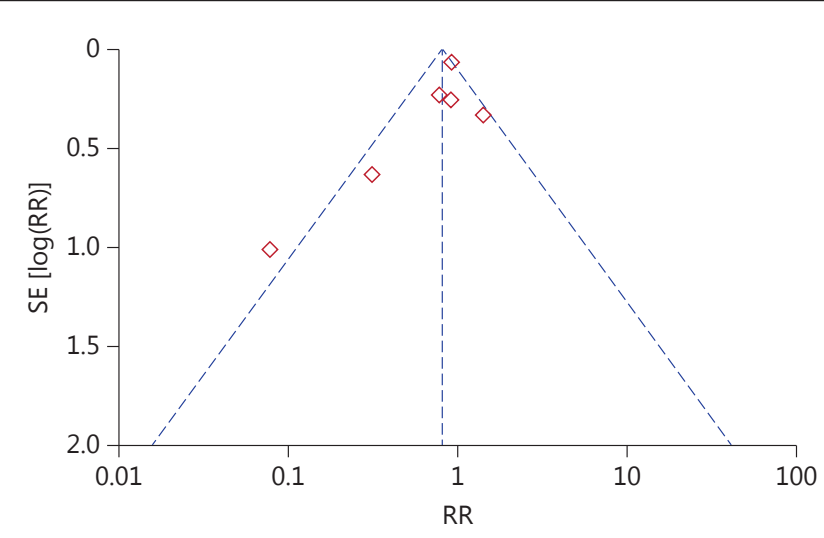

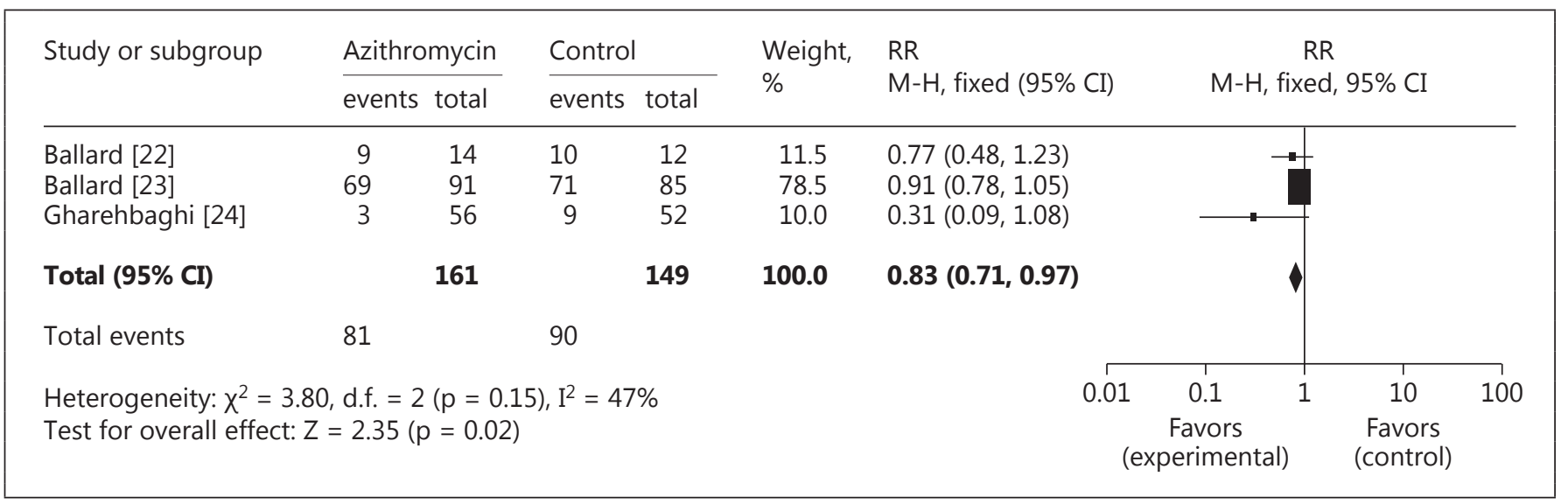

Fig. 3. Forest plot for effect of prophylactic azithromycin on the incidence of BPD.

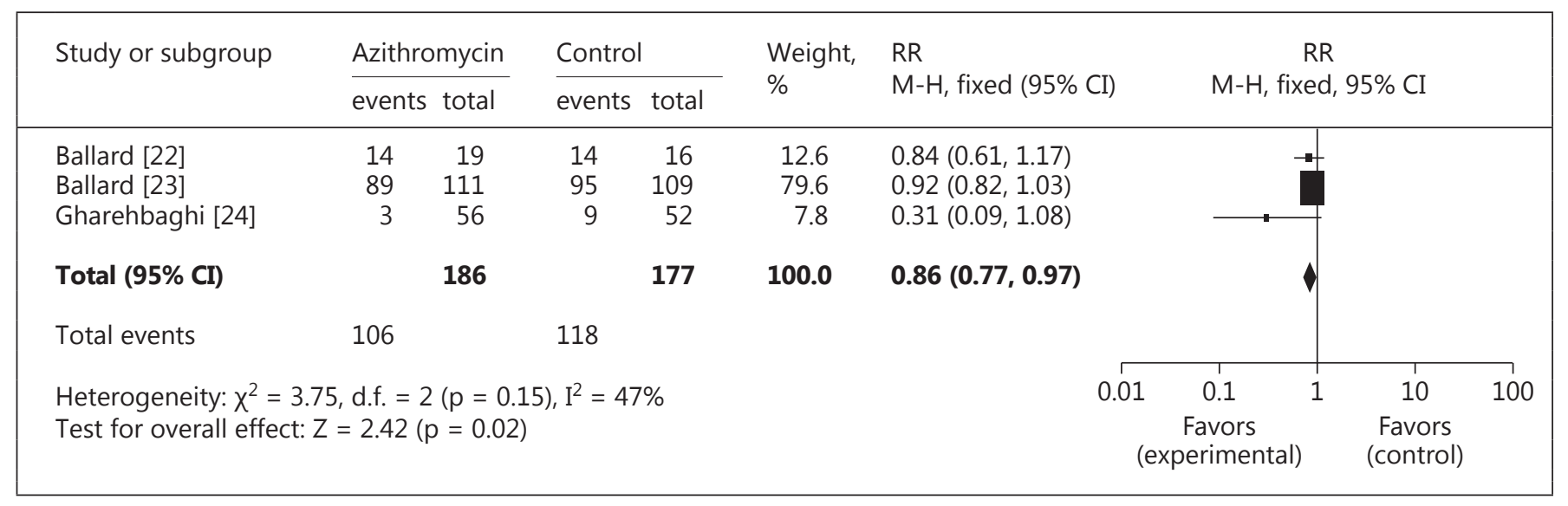

Fig. 4. Forest plot for effect of prophylactic azithromycin on BPD/death. 


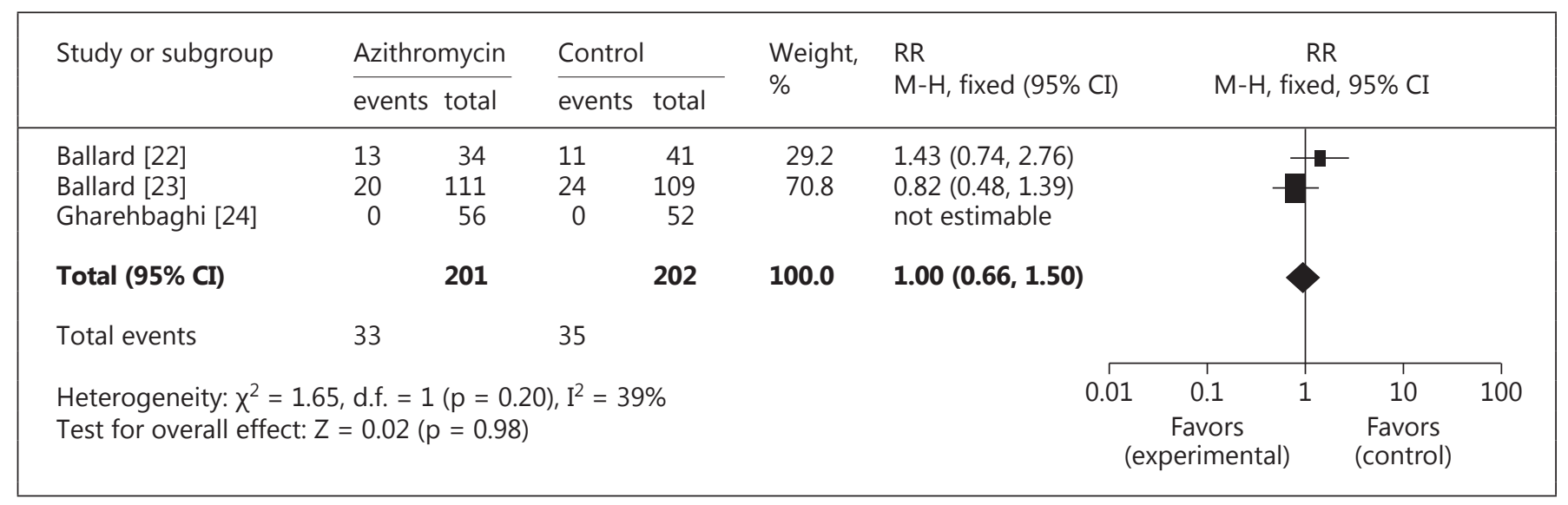

Fig. 5. Forest plot for effect of prophylactic azithromycin on death.

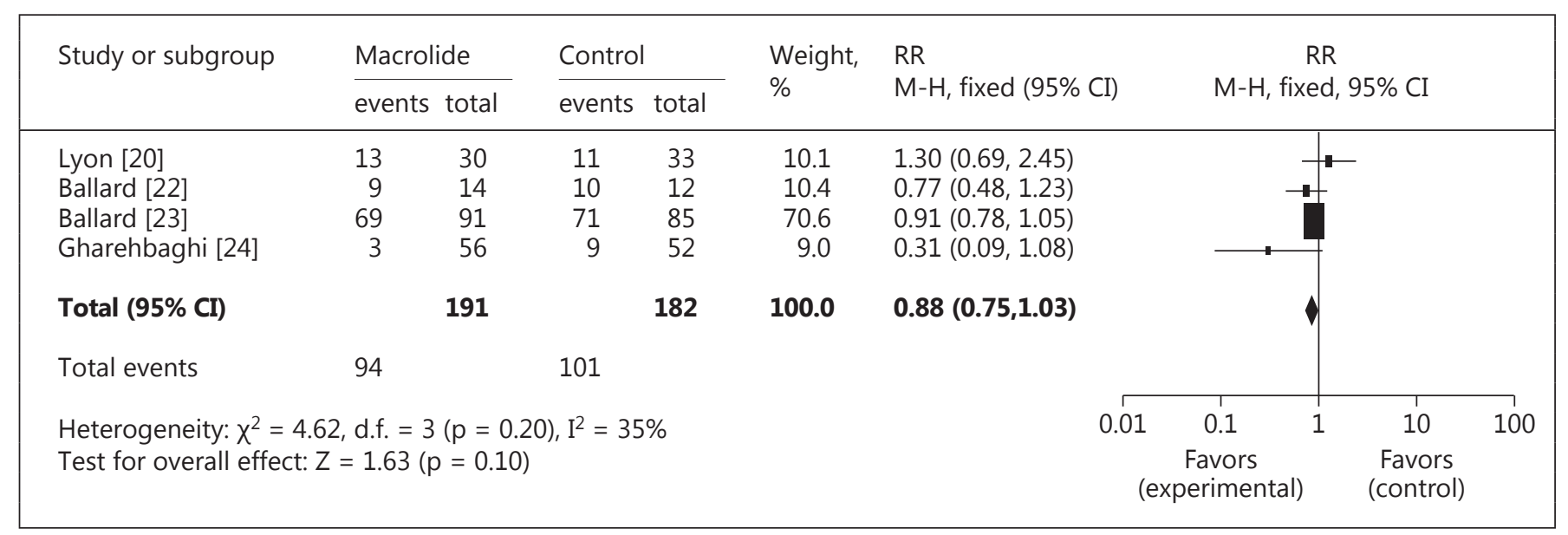

Fig. 6. Forest plot for effect of prophylactic macrolides on the incidence of BPD.

\begin{tabular}{|c|c|c|c|c|c|c|c|c|c|c|}
\hline \multirow{3}{*}{$\begin{array}{l}\text { Study or subgroup } \\
\text { Lyon [20] }\end{array}$} & \multirow{2}{*}{\multicolumn{2}{|c|}{$\frac{\text { Macrolide }}{\text { events total }}$}} & \multicolumn{2}{|c|}{ Control } & \multirow{3}{*}{$\begin{array}{l}\text { Weight, } \\
\% \\
20.3\end{array}$} & \multirow{2}{*}{$\begin{array}{l}\text { RR } \\
M-H, \text { fixed }(95 \% \mathrm{CI})\end{array}$} & \multirow{2}{*}{\multicolumn{3}{|c|}{$\begin{array}{c}R R \\
M-H \text {, fixed, 95\% CI }\end{array}$}} & \\
\hline & & & \multicolumn{2}{|c|}{ events total } & & & & & & \\
\hline & 4 & 34 & 8 & 41 & & $0.60(0.20,1.83)$ & & & & \\
\hline Ballard [22] & 5 & 19 & 4 & 16 & 12.1 & $1.05(0.34,3.27)$ & & & & \\
\hline Ballard [23] & 20 & 111 & 24 & 109 & 67.6 & $0.82(0.48,1.39)$ & & & & \\
\hline Gharehbaghi [24] & 0 & 56 & 0 & 52 & & not estimable & & & & \\
\hline Total $(95 \% \mathrm{CI})$ & & 220 & & 218 & 100.0 & $0.80(0.52,1.25)$ & & & & \\
\hline Total events & 29 & & 36 & & & & & & & \\
\hline Heterogeneity: $x^{2}=$ & , d.f. & $(p=c$ & $\mathrm{I}^{2}=$ & & & 0.01 & 0.1 & 1 & 10 & 100 \\
\hline Test for overall effe & $=0.9$ & $p=0.3$ & & & & & $\begin{array}{r}\text { Favor } \\
\text { xperime }\end{array}$ & & $\begin{array}{l}\text { Favors } \\
\text { (control) }\end{array}$ & \\
\hline
\end{tabular}

Fig. 7. Forest plot for effect of prophylactic macrolides on death. 


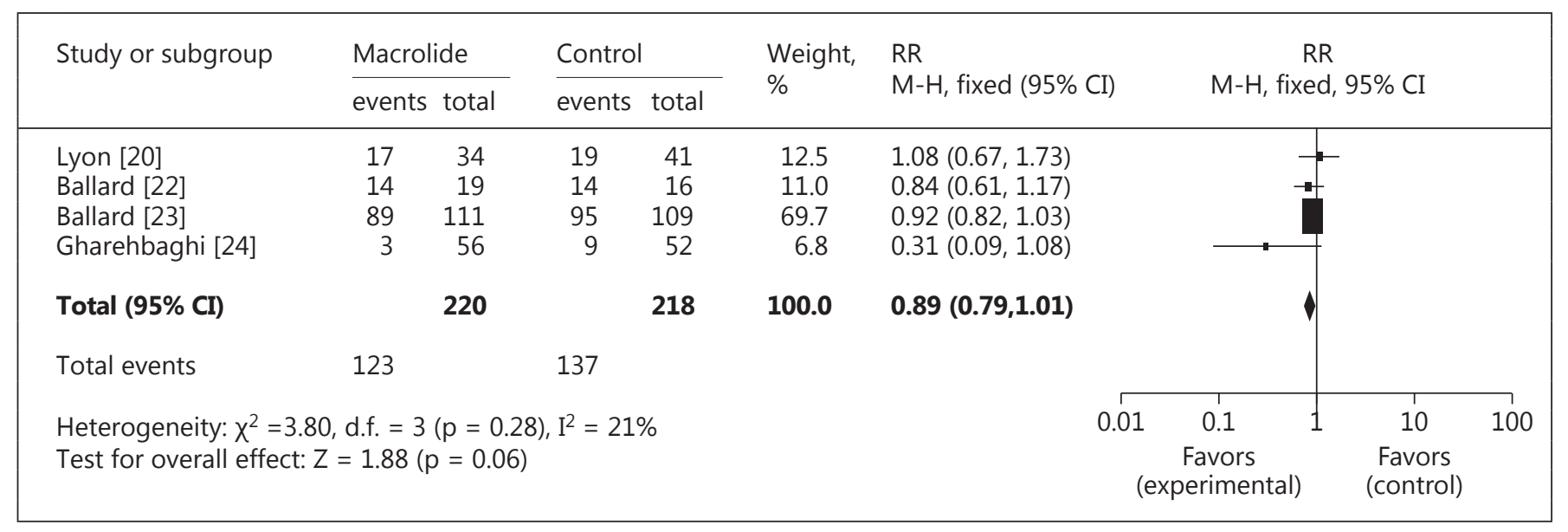

Fig. 8. Forest plot for effect of prophylactic macrolides on BPD/death.

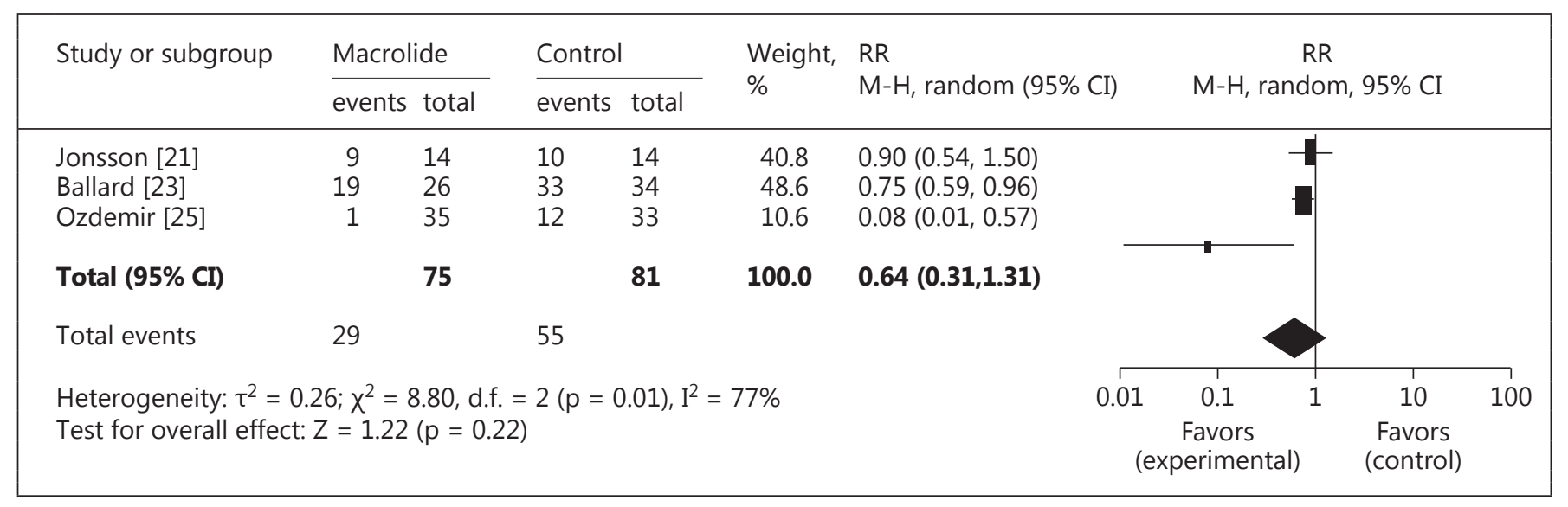

Fig. 9. Forest plot for effect of macrolides on the incidence of BPD among Ureaplasma-positive infants.

Effect of Macrolides in Ureaplasma-Positive Infants

In this analysis, 3 studies (using erythromycin, azithromycin, and clarithromycin) were included with a total of 156 infants $[21,23,25]$. The meta-analysis did not demonstrate a reduction of BPD (RR 0.64, 95\% CI 0.31-1.31), death (RR $0.84,95 \%$ CI $0.39-1.81$ ) or the composite outcome of BPD/death (RR 0.41,95\% CI 0.05-3.13; fig. 9-11). Only 2 studies were available for the analysis of death and the composite outcome of BPD/death $[23,25]$. Jonsson et al. [21] reported one neonatal death, but it was unclear if the infant belonged to the macrolides or control group.

\section{Secondary Outcomes}

Two important secondary outcomes of interest were the duration of ventilation and the hospital stay. There were no uniform secondary outcomes reported in these studies except for the duration of ventilation. However, analysis was challenging due to different formats of reporting. We could not combine the results as some studies reported the duration of ventilation [22-24] as mean while others reported it as median [20,21]. In the study by Lyon et al. [20], there was no significant difference in inflammatory markers between the two groups, and none of the other trials have studied the role of inflammatory markers. We also examined whether use of macrolides for a relatively longer period led to superadded bacterial or fungal infections. Only 4 studies reported sepsis data with incomplete description of sepsis [22-25]. Hence, analysis was not possible. 


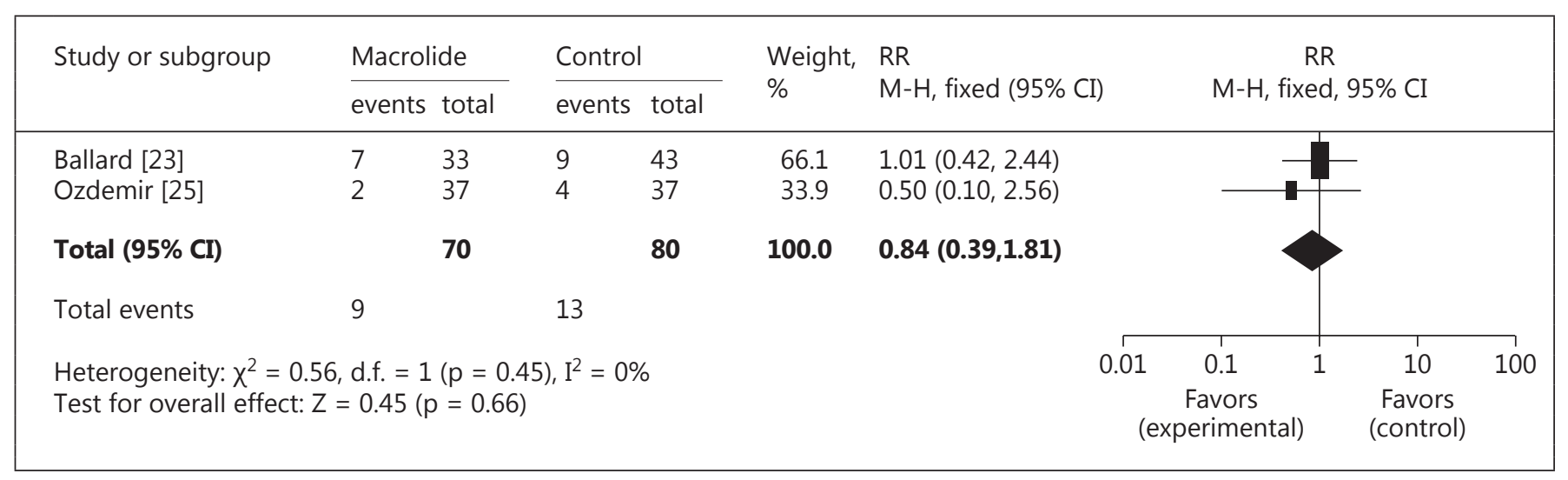

Fig. 10. Forest plot for effect of macrolides on death among Ureaplasma-positive infants.

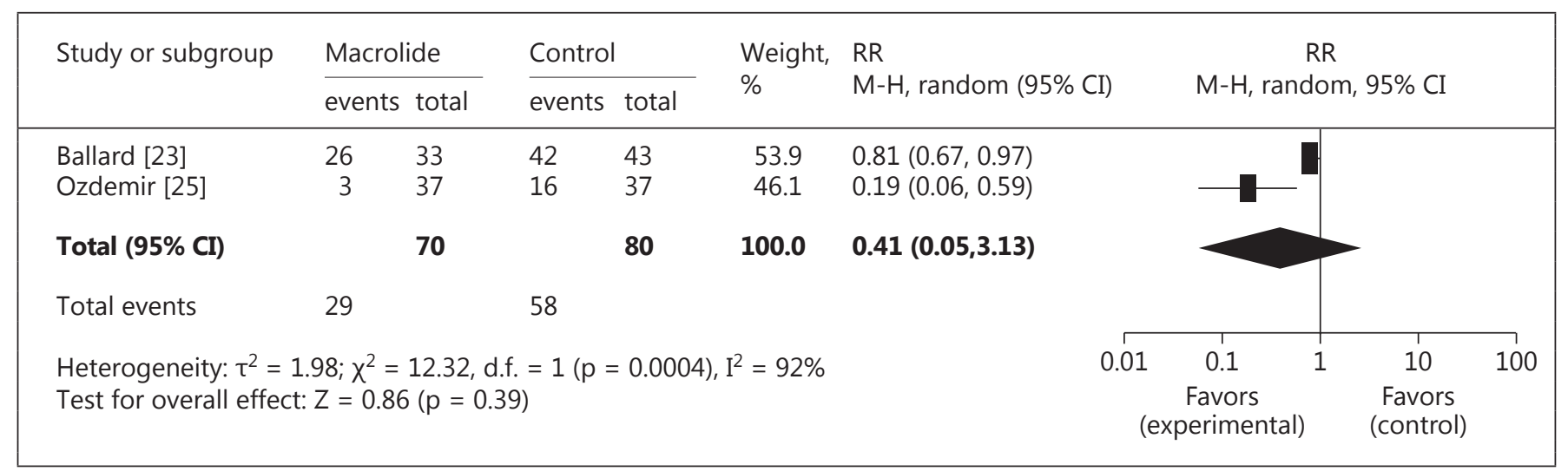

Fig. 11. Forest plot for effect of macrolides on BPD/death among Ureaplasma-positive infants.

\section{Discussion}

To the best of our knowledge, this is largest systematic review on this topic to answer a clinically important question. We analyzed the therapeutic use of macrolides in Ureaplasma-positive preterm infants and prophylactic macrolide treatment separately. We also analyzed the effect of most commonly used macrolide, azithromycin, on the incidence of BPD and composite outcome of BPD/ death.

The present meta-analysis demonstrates statistically significant reduction in the BPD or composite outcome of BPD/death when azithromycin was used prophylactically in preterm infants. Ten infants need to be treated prophylactically with azithromycin to prevent one case of $\mathrm{BPD}$. However, on combining all the studies, irrespective of the type of macrolides used, we observed no significant reduction in $\mathrm{BPD}$, although there was a trend towards reduction in BPD and composite outcome of BPD/death.

The previous Cochrane review on use of erythromycin for prevention of BPD included 2 studies, one with therapeutic use of erythromycin to Ureaplasma-positive infants and another given prophylactically [26]. We did not perform separate analysis, as there were no new studies using erythromycin. Similarly, we could not do metaanalysis for clarithromycin as only one study was identified.

Clinical isolates of Ureaplasma have been found to be susceptible to other macrolides such as azithromycin and clarithromycin with in vitro antibacterial activity superior to that of erythromycin [27]. Azithromycin and clarithromycin achieve better drug concentration in lung ep- 
ithelium and alveolar macrophages than erythromycin [28]. In a recent systematic review of 24 trials in pediatric upper respiratory tract infection, clarithromycin was therapeutically equivalent to other antibiotics, but has better bacteriological eradication and lower adverse effects [29].

The study by Ballard et al. [23] contributed to almost one third of the population in this meta-analysis. They used azithromycin in the dose of $10 \mathrm{mg} / \mathrm{kg} /$ day for a maximum duration of 6 weeks and did not observe significant reduction in the BPD. This is probably explained by the fact that azithromycin at this dose may not be effective in Ureaplasma clearance and suppression of inflammatory cytokines [30]. A recent pharmacokinetic study of azithromycin showed $20 \mathrm{mg} / \mathrm{kg} /$ day for 3 days might have better Ureaplasma clearance and anti-inflammatory action as well as safety [31]. In vitro susceptibility studies on Ureaplasma showed that clarithromycin was the most active macrolide with minimal inhibitory concentration (MIC) $0.25 \mu \mathrm{g} / \mathrm{ml}$ as compared to erythromycin and azithromycin with MIC of $2 \mu \mathrm{g} / \mathrm{ml}$ [32].

The main limitation of our analysis is due to primary studies included and their methodologies. Of the 6 studies included in the analysis, the 2 erythromycin studies were published 16 years ago with lots of changes in neonatal intensive care unit practice and BPD rate since that time.

The choice and dosage of macrolides were empirically chosen and were not based on any pharmacokinetic studies. The types of macrolide, their dosages, method of Ureaplasma detection, the time of initiation of macrolides and duration of treatment varied among the studies. Lyon et al. [20], Jonsson et al. [21], and Ballard et al. [22] employed tracheal aspirate culture for detection of Ureaplasma. In the subsequent study by Ballard et al. [23], they used polymerase chain reaction (PCR) techniques on tracheal aspirates and Ozdemir et al. [25] used nasopharyngeal aspirate for Ureaplasma detection. Except for one study [23], most of the studies included in the analysis were of small sample size and only two studies were of high quality $[23,24]$. Most of the studies did not report the potential side effects such as nosocomial sepsis and NEC. There was limited information on the duration of hospital stay and feeding intolerance. Randomized trials that used prophylactic macrolides showed a trend towards significance, possibly explaining the fact that early control of infection/inflammation may play a role in prevention of BPD. However, this may be reflective of the high prevalence of BPD (84\%) in the included studies and 2 out of 3 studies are from the same center [22, 23].
Perinatal infection is an independent risk factor for BPD. Treatment of perinatal infection with antibiotics may reduce the neonatal morbidities by prolonging pregnancy or reducing infection-related inflammation. A recent Cochrane review on antibiotics for preterm premature rupture of membrane (PPROM) showed only shortterm benefits, and there was no difference in the incidence of BPD [33]. Though Ureaplasma is the most common commensal in the maternal genital tract, about $22 \%$ of mothers with PPROM or preterm labor will have evidence of Ureaplasma infection. Therefore, routine treatment of all pregnant women with PPROM or preterm labor will in many cases be unnecessary. Although the NNT in this meta-analysis was 10 , the incidence of BPD is variable and only a third of the preterm infants are colonized with Ureaplasma spp., clinicians should be cautious while using the prophylactic macrolide therapy as it may lead to unnecessary treatment of many preterm infants. Prolonged antibiotic therapy should be avoided in preterm neonates because prolonged antibiotic exposure has been associated with increased rates of NEC, late-onset sepsis and death [34].

Several studies in adults have highlighted the association between macrolide use and cardiovascular events, notably arrhythmias and death $[35,36]$. In 2013, the United States Food and Drug Administration issued drug alert regarding the use of azithromycin especially in high-risk patients such as those with known prolonged QTc syndromes, on drugs known to prolong QTc and proarrhythmogenic conditions. These events have not been described in the neonatal literature. However, the physicians caring for preterm infants should be aware of this potential side effect. In a recent study by Lund et al. [37], use of macrolides, notably erythromycin, during the first 14 days of life was significantly associated with infantile hypertrophic pyloric stenosis. Until further studies are available, caution is required for routine clinical use of macrolides in BPD prevention.

Since BPD is a multifactorial disease, it is unlikely that a single treatment modality will be completely effective in preventing BPD. It is essential to conduct pharmacokinetic studies to find the macrolide of choice, dosage schedule, formulation and duration of treatment. Apart from the clinical outcomes, it is important to understand the anti-inflammatory and antimicrobial properties of macrolides, to study Ureaplasma clearance with macrolides as well as levels of inflammatory markers following treatment. 


\section{Conclusion}

In this meta-analysis, azithromycin when given prophylactically is associated with reduction in BPD and $\mathrm{BPD} /$ death in preterm infants. However, studies combining all macrolides when used either prophylactically or therapeutically in Ureaplasma-colonized ventilated preterm infants did not reduce BPD or composite outcome of $\mathrm{BPD} /$ death. With infection/inflammation playing a major role in the pathogenesis of BPD and in the era where no effective treatment for BPD exists, randomized control trials with macrolides are not unreasonable. However, high-quality pharmacokinetic studies are needed before routine use of azithromycin in the neonatal intensive care units.

\section{Disclosure Statement}

None.

\section{References}

1 Schmidt B, Asztalos EV, Roberts RS, et al: Impact of bronchopulmonary dysplasia, brain injury, and severe retinopathy on the outcome of extremely low-birth-weight infants at 18 months: results from the trial of indomethacin prophylaxis in preterms. JAMA 2003; 289:1124-1129.

- 2 Ehrenkranz RA, Walsh MC, Vohr BR, et al: Validation of the national institutes of health consensus definition of bronchopulmonary dysplasia. Pediatrics 2005;116:1353-1360.

-3 Speer CP: Chorioamnionitis, postnatal factors and proinflammatory response in the pathogenetic sequence of bronchopulmonary dysplasia. Neonatology 2009;95:353-361.

-4 Goldenberg RL, Andrews WW, Goepfert AR, et al: The Alabama Preterm Birth Study: Umbilical cord blood Ureaplasma urealyticum and Mycoplasma hominis cultures in very preterm newborn infants. Am J Obstet Gynecol 2008;198:43.e1-43.e5.

5 Collins JJP, Kallapur SG, Knox CL, et al: Repeated intrauterine exposures to inflammatory stimuli attenuated transforming growth factor- $\beta$ signaling in the ovine fetal lung. Neonatology 2013;104:49-55.

-6 Kotecha S, Hodge R, Schaber JA, Miralles R, Silverman M, Grant WD: Pulmonary Ureaplasma urealyticum is associated with the development of acute lung inflammation and chronic lung disease in preterm infants. Pediatr Res 2004;55:61-68.

7 Wang EE, Ohlsson A, Kellner JD: Association of Ureaplasma urealyticum colonization with chronic lung disease of prematurity: results of a metaanalysis. J Pediatr 1995;127:640-644.

8 Schelonka RL, Katz B, Waites KB, Benjamin DK Jr: Critical appraisal of the role of Ureaplasma in the development of bronchopulmonary dysplasia with meta-analytic techniques. Pediatr Infect Dis J 2005;24:10331039.

\9 Gravett MG, Novy MJ, Rosenfeld RG, et al: Diagnosis of intra-amniotic infection by proteomic profiling and identification of novel biomarkers. JAMA 2004;292:462-469.
10 Moss TJ, Knox CL, Kallapur SG, et al: Experimental amniotic fluid infection in sheep: effects of Ureaplasma parvum serovars 3 and 6 on preterm or term fetal sheep. Am J Obstet Gynecol 2008;198:122.e1-122.e8.

11 Li YH, Brauner A, Jonsson B, et al: Ureaplasma urealyticum-induced production of proinflammatory cytokines by macrophages. Pediatr Res 2000;48:114-119.

12 Li YH, Chen M, Brauner A, Zheng C, Skov Jensen J, Tullus K: Ureaplasma urealyticum induces apoptosis in human lung epithelial cells and macrophages. Biol Neonate 2002;82: 166-173.

13 Ozdemir R, Sari FN, Tunay ZO, et al: The association between respiratory tract Ureaplasma urealyticum colonization and severe retinopathy of prematurity in preterm infants $</=1,250$ g. Eye (Lond) 2012;26:992-996.

14 Kasper DC, Mechtler TP, Bohm J, et al: In utero exposure to Ureaplasma spp. is associated with increased rate of bronchopulmonary dysplasia and intraventricular hemorrhage in preterm infants. J Perinat Med 2011;39: 331-336.

15 Viscardi RM, Hashmi N, Gross GW, Sun CC, Rodriguez A, Fairchild KD: Incidence of invasive Ureaplasma in VLBW infants: relationship to severe intraventricular hemorrhage. J Perinatol 2008;28:759-765.

16 Okogbule-Wonodi AC, Gross GW, Sun CC, et al: Necrotizing enterocolitis is associated with Ureaplasma colonization in preterm infants. Pediatr Res 2011;69:442-447.

17 Berger A, Witt A, Haiden N, et al: Intrauterine infection with Ureaplasma species is associated with adverse neuromotor outcome at 1 and 2 years adjusted age in preterm infants. J Perinat Med 2009;37:72-78.

18 Jaffe A, Bush A: Anti-inflammatory effects of macrolides in lung disease. Pediatr Pulmonol 2001;31:464-473.

19 Aghai ZH, Kode A, Saslow JG, et al: Azithromycin suppresses activation of nuclear factor-kappa B and synthesis of pro-inflammatory cytokines in tracheal aspirate cells from premature infants. Pediatr Res 2007;62:483488.
20 Lyon AJ, McColm J, Middlemist L, Fergusson S, McIntosh N, Ross PW: Randomized trial of erythromycin on the development of chronic lung disease in preterm infants. Arch Dis Child Fetal Neonatal Ed 1998;78:F10-F14.

21 Jonsson B, Rylander M, Faxelius G: Ureaplasma urealyticum, erythromycin and respiratory morbidity in high-risk preterm neonates. Acta Paediatr 1998;87:1079-1084.

22 Ballard HO, Anstead MI, Shook LA: Azithromycin in the extremely low birth weight infant for the prevention of bronchopulmonary dysplasia: a pilot study. Respir Res 2007;8:41.

23 Ballard HO, Shook LA, Bernard P, et al: Use of azithromycin for the prevention of bronchopulmonary dysplasia in preterm infants: a randomized, double-blind, placebo controlled trial. Pediatr Pulmonol 2011;46:111118.

24 Gharehbaghi MM, Peirovifar A, Ghojazadeh M, Mahallei M: Efficacy of azithromycin for prevention of bronchopulmonary dysplasia (BPD). Turk J Med Sci 2012;42:1070-1075.

25 Ozdemir R, Erdeve O, Dizdar EA, et al: Clarithromycin in preventing bronchopulmonary dysplasia in Ureaplasma urealyticum-positive preterm infants. Pediatrics 2011;128:e1496e1501.

26 Mabanta CG, Pryhuber GS, Weinberg GA, Phelps DL: Erythromycin for the prevention of chronic lung disease in intubated preterm infants at risk for, or colonized or infected with Ureaplasma urealyticum. Cochrane Database Syst Rev 2003;CD003744.

27 Abele-HornM, Becher C, Bauernfeind A, et al: Comparative in vitro susceptibility of Ureaplasma urealyticum and Mycoplasma hominis to macrolides, tetracyclines, 4-quinolones, chloramphenicol, gentamicin, and clindamycin. Antiinfect Drugs Chemother 1996;14:171-173. 
28 Togami K, Chono S, Morimoto K: Distribution characteristics of clarithromycin and azithromycin, macrolide antimicrobial agents used for treatment of respiratory infections, in lung epithelial lining fluid and alveolar macrophages. Biopharm Drug Dispos 2011; 32:389-397.

29 Gutierrez-Castrellon P, Mayorga-Buitron JL, Bosch-Canto V, Solomon-Santibanez G, de Colsa-Ranero A: Efficacy and safety of clarithromycin in pediatric patients with upper respiratory infections: a systematic review with meta-analysis. Rev Invest Clin 2012;64: 126-135.
30 Waites KB, Crouse DT, Cassell GH: Antibiotic susceptibilities and therapeutic options for Ureaplasma urealyticum infections in neonates. Pediatr Infect Dis J 1992;11:23-29.

31 Hassan HE, Othman AA, Eddington ND, Duffy L, Xiao L, Waites KB, et al: Pharmacokinetics, safety, and biologic effects of azithromycin in extremely preterm infants at risk for Ureaplasma colonization and bronchopulmonary dysplasia. J Clin Pharmacol 2011;51: 1264-1275.

32 Samra Z, Rosenberg S, Dan M: Susceptibility of Ureaplasma urealyticum to tetracycline, doxycycline, erythromycin, roxithromycin, clarithromycin, azithromycin, levofloxacin and moxifloxacin. J Chemother 2011;23:7779.

-33 Kenyon S, Boulvain M, Neilson JP: Antibiotics for preterm rupture of membranes. Cochrane Database Syst Rev 2013;CD001058.
34 Cotton CM, Taylor S, Stoll B, et al: Prolonged duration of initial empirical antibiotic treatment is associated with increased rates of necrotizing enterocolitis and death for extremely low birth weight infants. Pediatrics 2009;123: 58-66.

35 Abo-Salem E, Fowler JC, Attari M, Cox CD, Perez-Verdia A, Panikkath R, Nugent K: Antibiotic-induced cardiac arrhythmias. Cardiovasc Ther 2014;32:19-25.

36 Ray WA, Murray KT, Hall K, Arbogast PG, Stein CM: Azithromycin and the risk of cardiovascular death. N Engl J Med 2012;366: 1881-1890.

37 Lund M, Pasternak B, Davidsen RB, et al: Use of macrolides in mother and child and risk of infantile hypertrophic pyloric stenosis: nationwide cohort study. BMJ 2014;348:1-10. 